\title{
Comparative use of exercise tolerance testing, SPECT and CMR, alone and in combination, for the diagnosis of coronary heart disease in the CE-MARC study
}

John P Greenwood ${ }^{1}$, Neil Maredia', Julia Brown², John Younger ${ }^{1}$, Colin Everett ${ }^{2}$, Jane Nixon², Catherine J Dickinson ${ }^{3}$, Sven Plein ${ }^{1 *}$

From 16th Annual SCMR Scientific Sessions

San Francisco, CA, USA. 31 January - 3 February 2013

\section{Background}

Whilst exercise tolerance testing (ETT) has been a corner stone investigation for the diagnosis of patients with suspected angina, increasingly imaging techniques have gained prominence. We aimed to determine the diagnostic accuracy of ETT in the CE-MARC study population compared to single photon emission computed tomography (SPECT) and cardiovascular magnetic resonance (CMR) and to examine the clinical utility of performing CMR or SPECT after an inconclusive ETT result.

\section{Methods}

CE-MARC was the largest prospective real-world evaluation of CMR, SPECT and ETT, in 752 patients with suspected angina. Results for CMR and SPECT have been reported. For this analysis, results of the ETT were analysed and compared with CMR and SPECT as well as combinations of tests.

\section{Results}

580 patients had ETT and angiography (disease prevalence $39 \%)$. The sensitivity, specificity, positive and negative predictive values $(95 \% \mathrm{CI})$ of ETT were $68.3(61.9,74.0), 72.5$
(67.6, 76.9), $61.0(54.8,66.8), 78.4(73.7,82.5)$. All four study tests (ETT, CMR, SPECT and coronary angiography) were undertaken in 503 patients, in which SPECT or CMR were used to adjudicate on the inconclusive ETT tests. Combined ETT and CMR had significantly superior sensitivity and negative predictive value compared to combined ETT and SPECT ( $\mathrm{P}=0.0266, \mathrm{P}=0.0114$ respectively) but the specificities and PPV's were similar. Combined ETT and SPECT compared to SPECT alone resulted in improved sensitivity ( $86.3 \%$ vs. $65.5 \%)$ and negative predictive value $(79.0 \%$ vs. $87.9 \%)$ but at a cost of reduced specificity and positive predictive values $(83.7 \%$ vs. $64.1 \% ; 72.1 \%$ vs. 60.7\%). Overall, the combined ETT and CMR strategy did not outperform CMR alone.

\section{Conclusions}

CMR provides more accurate diagnostic information than ETT, SPECT or a combination of the two, in patients with suspected stable angina.

\section{Funding}

CE-MARC was funded by the British Heart Foundation (BHF). SP is funded by a BHF fellowship.

'LIGHT Institute, University of Leeds, Leeds, UK

Full list of author information is available at the end of the article

(c) 2013 Greenwood et al; licensee BioMed Central Ltd. This is an Open Access article distributed under the terms of the Creative 


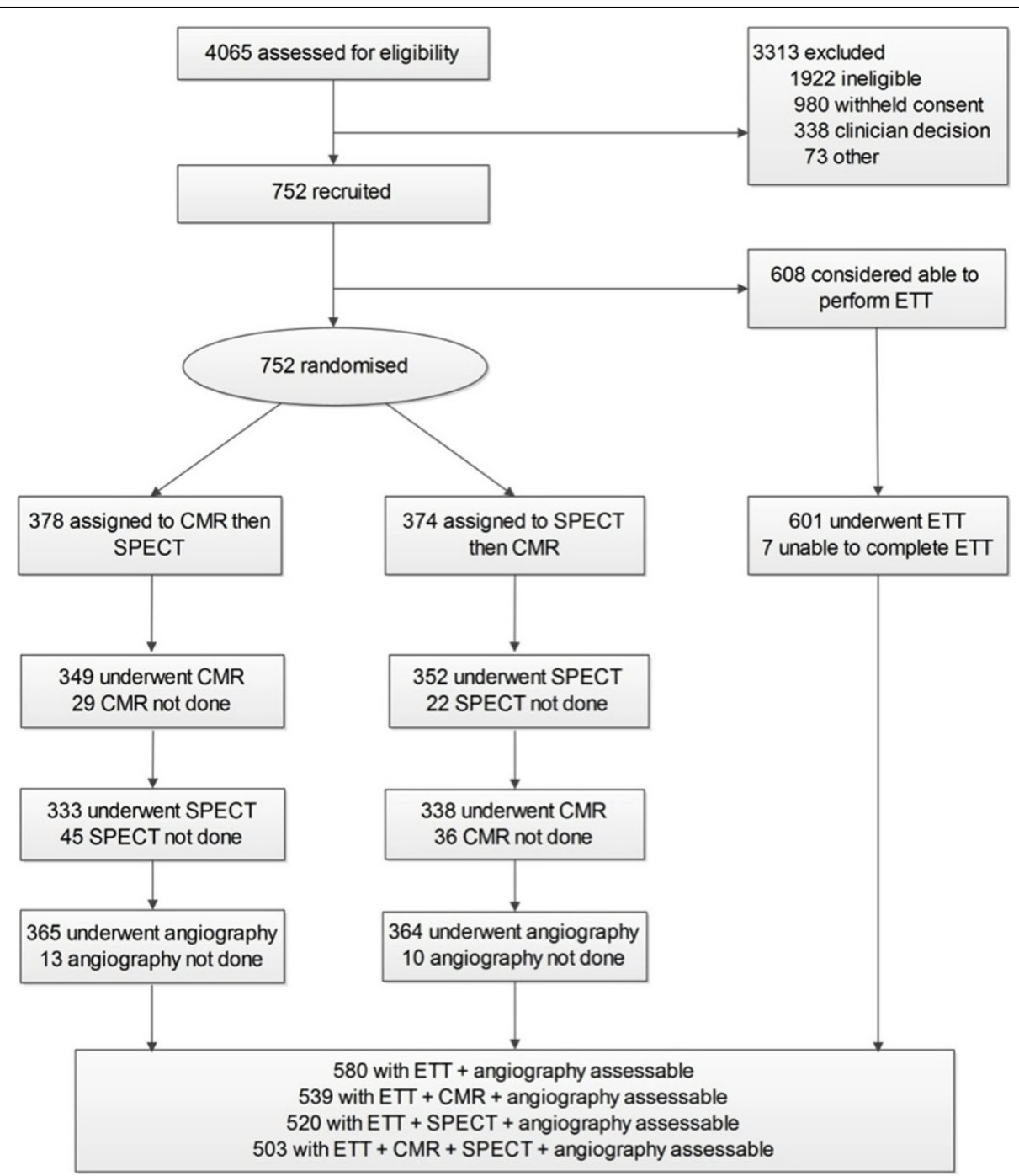

Figure 1 Patient flow diagram.

\section{Author details}

${ }^{1}$ LIGHT Institute, University of Leeds, Leeds, UK. ${ }^{2}$ Clinical Trials Research Unit,

University of Leeds, Leeds, UK. ${ }^{3}$ Department of Nuclear Cardiology, Leeds

Teaching Hospitals, Leeds, UK.

Published: 30 January 2013

doi:10.1186/1532-429X-15-S1-010

Cite this article as: Greenwood et al:: Comparative use of exercise tolerance testing, SPECT and CMR, alone and in combination, for the diagnosis of coronary heart disease in the CE-MARC study. Journal of Cardiovascular Magnetic Resonance 2013 15(Suppl 1):010.

\section{Submit your next manuscript to BioMed Central} and take full advantage of:

- Convenient online submission

- Thorough peer review

- No space constraints or color figure charges

- Immediate publication on acceptance

- Inclusion in PubMed, CAS, Scopus and Google Scholar

- Research which is freely available for redistribution

Submit your manuscript at www.biomedcentral.com/submit 